\title{
Medicare immunosuppressant coverage and access to kidney transplantation: a retrospective national cohort study
}

\author{
Vanessa Grubbs ${ }^{1 *}$, Laura C Plantinga ${ }^{2}$, Eric Vittinghoff ${ }^{3}$, Ann M O'Hare $^{4}$ and R Adams Dudley ${ }^{5}$
}

\begin{abstract}
Background: In December 2000, Medicare eliminated time limitations in immunosuppressant coverage after kidney transplant for beneficiaries age $\geq 65$ and those who were disabled. This change did not apply to younger nondisabled beneficiaries who qualified for Medicare only because of their end-stage renal disease (ESRD). We sought to examine access to waitlisting for kidney transplantation in a cohort spanning this policy change.

Methods: This was a retrospective cohort analysis of 241,150 Medicare beneficiaries in the United States Renal Data System who initiated chronic dialysis between 1/1/96 and 11/30/03. We fit interrupted time series Cox proportional hazard models to compare access to kidney transplant waitlist within 12 months of initiating chronic dialysis by age/disability status, accounting for secular trends.

Results: Beneficiaries age $<65$ who were not disabled were less likely to be waitlisted after the policy change (hazard ratio (HR) for the later vs. earlier period, $0.93, p=0.002$ ), after adjusting for sociodemographic factors, co-morbid conditions, income, and ESRD network. There was no evidence of secular trend in this group (HR per year, 1.00, $p=0.989$ ). Likelihood of being waitlisted among those age $\geq 65$ or disabled increased steadily throughout the study period (HR per year, 1.04, $p<0.001$ ), but was not clearly affected by the policy change (HR for the immediate effect of policy change, $0.93, p=0.135$ ).

Conclusions: The most recent extension in Medicare immunosuppressant coverage appears to have had little impact on the already increasing access to waitlisting among $\geq 65$ / disabled beneficiaries eligible for the benefit but may have decreased access for younger, non-disabled beneficiaries who were not. The potential ramifications of policies on candidacy appeal for access to kidney transplantation should be considered.
\end{abstract}

\section{Background}

Because demand for donor kidneys exceeds supply several-fold [1], transplant centers are forced to make difficult decisions about who should receive transplantable organs. Central to the long-standing debate on how to allocate this scarce resource is the concept of equityequal utilization of resources for equal need [2]-as women, the poor, and racial/ethnic minorities have historically been less likely to receive transplants than men, the wealthy, and non-Hispanic whites [3].

Health inequities may be influenced by policy [4]. When the Medicare end-stage renal disease (ESRD)

\footnotetext{
*Correspondence: grubbsv@medsfgh.ucsf.edu

'Division of Nephrology, University of California San Francisco, San Francisco General Hospital, San Francisco, CA, USA

Full list of author information is available at the end of the article
}

program was established in 1973 rates of allograft survival were quite low. Therefore, immunosuppressant coverage created by the Omnibus Reconciliation Act of 1986 was limited to 1 year and incrementally extended to 3 years by mid-1995. In an effort to alleviate concerns of senior citizens being unable to afford their medications, the Beneficiary Improvement and Protection Act (BIPA) was passed in December 2000 to further extend coverage to lifetime-but only for Medicare beneficiaries whose eligibility was based on age or having a disability other than end-stage renal disease (ESRD) [5].

Several studies have shown that transplant recipients are at increased risk of medication noncompliance and subsequent graft loss if they are not able to afford their medications [6-8] and that incremental extensions in immunosuppressant coverage have been shown to have a 
positive effect on graft survival. Woodward and colleagues showed that, while graft survival at 3 years posttransplant was significantly lower for low- vs. highincome kidney transplant recipients when coverage was provided for only 1 year, there were no differences in 3-year graft survival by income when coverage was extended to 3 years [9]. They found similar improvements in graft survival among low-income recipients eligible for lifetime coverage [10].

Given the association between graft survival and immunosuppressant coverage, it is possible that Medicare immunosuppressant policy may also impact "upstream" care processes such as listing for transplant. ESRD patients without sufficient insurance coverage or financial resources may be viewed as less ideal transplant candidates and, therefore, may be less likely to be waitlisted. Though older patients with ESRD and those with extrarenal co-morbidities have historically been considered less ideal candidates than younger patients and those with fewer co-morbidities because of perceived surgical risk and decreased transplant and patient survival [1119], the extension of lifetime immunosuppressant coverage to this group by BIPA may have increased their candidacy appeal. Therefore, we hypothesized that expansion of immunosuppressant coverage would differentially impact access to waitlisting for kidney transplantation depending on eligibility for it: with access increasing among older/ disabled beneficiaries who would always have insurance coverage for immunosuppressants, but decreasing among younger/non-disabled beneficiaries who might not be able to afford their medications when Medicare eligibility ended at three years post transplant and, therefore, be at risk of rejecting a scarce resource. We sought to test this hypothesis in a population of Medicare beneficiaries who initiated dialysis within the years spanning the policy change.

\section{Methods}

\section{Study sample}

Using standard analysis files obtained with permission from the United States Renal Data System (USRDS), a national ESRD registry, we assembled a cohort of Medicare beneficiaries between the ages of 21 and 75 years who initiated chronic dialysis between $1 / 1 / 96$ and $11 / 30$ / 03 . Individuals under 21 years were excluded from the analysis because children are subject to a different selection algorithm for kidney transplant [20] and those under 21 may have insurance coverage through their parents. Individuals over 75 years were excluded because this group receives $<1 \%$ of all kidney transplants $[13,21]$. Beneficiaries who were waitlisted prior to initiating dialysis were excluded because preemptive waitlisting requires resources and early nephrology referral-factors that vary by insurance status, income, and race $[22,23]-$ and our goal was to assess the policy's effect among uniformly resourced cohorts.

We limited our study to patients with Medicare as their sole insurer using the payer variable at 90 days post-dialysis initiation in the USRDS Core Payer History file, which is compiled from a monthly record of payment source for ESRD service for each patient. Only those with Medicare as primary payer were included. Those with private insurance or dual coverage (Medicare secondary payer, group health organization, or other) were excluded because private forms of health insurance have variable drug coverage and Medicaid immunosuppressant coverage varies across states. Patients were followed starting at 90 days after initiation of dialysis because patients under age 65 whose only entitlement to Medicare is ESRD must wait 3 months on dialysis before becoming eligible for Medicare. The cohort thus did not include beneficiaries who died or received a kidney transplant within the first 90 days after onset of ESRD.

\section{Data source}

The USRDS collects, analyzes, and distributes information on all treated ESRD patients in the United States. Data from the Patients file, the Medical Evidence file and Transplant and Payer History files were merged to create the final dataset. USRDS data also included participant ZIP code of residence, which we used to assign patients' median ZIP code-level income according to the 2000 U.S. Population Census.

\section{Primary predictors}

Our primary predictors were age/disability status and date of dialysis initiation. Disability was defined by employment status at time of dialysis initiation. Age and disability status were used to create a dichotomous age/ disability status variable defined as age $\geq 65$ years or disabled or age $<65$ years and non-disabled. Those who met Medicare eligibility for dialysis and were $\geq 65$ years or disabled were eligible for the lifetime immunosuppressant benefit after $1 / 1 / 01$.

\section{Outcome variables}

The primary outcome was access to kidney transplantation, defined as time from day 91 after initiating chronic dialysis (initial Medicare eligibility for dialysis) to placement on the kidney transplant waitlist with censoring at death or at 12 months after initial Medicare eligibility for dialysis. Our 12-month time period is a reasonable time period for patients to become accustomed to dialysis and undergo kidney transplant evaluation. The time period is consistent with Healthy People 2020 objectives for chronic kidney disease and is slightly longer than that agreed upon by consensus in a study by Ayanian et al. [24]. 


\section{Covariates}

Covariates included gender, race/ethnicity, income, primary cause of ESRD, co-morbid conditions at onset of ESRD, and ESRD network. We defined race/ethnicity as a categorical variable (non-Hispanic white (reference), non-Hispanic Black, Hispanic, or Other). We defined median ZIP code-level income in quartiles for the entire sample. Primary causes of ESRD as a 6-category indicator variable included diabetes (reference), hypertension, glomerular disease, cystic renal disease, other/unknown diagnosis. We adjusted our analyses using binary indicators (no (reference)/yes) for the following co-morbid conditions at the start of dialysis: congestive heart failure, ischemic heart disease, cerebrovascular accident, peripheral vascular disease, chronic obstructive pulmonary disease, tobacco abuse, drug dependence, and ability to ambulate. HIV without or with AIDS was defined as a three-level variable (no HIV/AIDS (reference)). We included a categorical variable for all but one of the 18 ESRD networks to account for geographic variability in access to renal transplant [25].

\section{Statistical analyses}

We fit interrupted time series (ITS) Cox proportional hazard models to examine differential effects of the new coverage policy on access to kidney transplant by age/ disability status, after adjusting for potential confounders. ITS is an established methodology that allows for different secular trends before and after the introduction of the new policy. This model accounts for the possibility that the intervention changes the trend, in which case simple pre-post comparisons can be misleading [26-29]. For each age/disability group, the full ITS model allowed for an abrupt change in the waitlisting rate at the beginning of 2001, as well as for different secular trends before and after the introduction of the new policy. If no statistically significant trends were found, we then simplified the model by including only the potential confounders. We assumed patients who initiated dialysis in 2000 and completed one year of follow-up in 2001 were affected by the new policy after $1 / 1 / 01$; this was implemented using time-dependent covariates. Results of this model are summarized by plotting the estimated probability of being waitlisted within 12 months by group and date of dialysis initiation, accounting for censoring and holding all covariates constant at their sample means; these calculations combined information from the baseline survival function and adjusted relative hazard estimates. All analyses were implemented in Stata Version 12.0 (Stata Corp., College Station, TX).

\section{Results}

There were 241,150 beneficiaries who met our study inclusion criteria and were included in the analysis. Of these, 76,228 (31.6\%) were age $<65 /$ non-disabled and $164,922(68.4 \%)$ were age $\geq 65 /$ disabled. Patient characteristics by age/disability status are shown in Table 1 . Those age $\geq 65 /$ disabled were more likely to be nonHispanic white (Figure 1), live in a high-income ZIP code, and have higher prevalent co-morbidities than their age $<65 /$ non-disabled counterparts. The absolute percentage of those waitlisted was higher among age $<65 /$ non-disabled patients than among the age $\geq 65 /$ disabled patients.

Table 1 Patient characteristics by age/disability status ${ }^{\text {a,c }}$

\begin{tabular}{|c|c|c|}
\hline & $\begin{array}{l}<65 / \text { Non-disabled } \\
N=76,228(31.6 \%)\end{array}$ & $\begin{array}{l}\geq 65 / \text { Disabled } \\
N=164,922(68.4 \%)\end{array}$ \\
\hline Waitlisted $(n, \%)$ & $7,199(9.4)$ & $6,062(3.7)$ \\
\hline Mean age, years (SD) & $50.5(11.1)$ & $65.0(9.6)$ \\
\hline Male $(n, \%)$ & $39,808(52.2)$ & $87,910(53.3))$ \\
\hline \multicolumn{3}{|l|}{ Race/Ethnicity (n,\%) } \\
\hline Non-Hispanic white & $29,042(38.1)$ & $94,249(57.1)$ \\
\hline Non-Hispanic black & $31,191(40.9)$ & $46,000(27.9)$ \\
\hline Hispanic & $12,140(15.9)$ & $18,974(11.5)$ \\
\hline Other & $3,855(5.1)$ & $5,699(3.5)$ \\
\hline \multicolumn{3}{|l|}{ Income quartile } \\
\hline$>75^{\text {th }}$ & $18,451(24.2)$ & $47,156(28.6)$ \\
\hline $50-75^{\text {th }}$ & $17,279(22.7)$ & $40,734(24.7)$ \\
\hline $25-50^{\text {th }}$ & $18,383(24.1)$ & $40,029(24.3)$ \\
\hline$<25$ th & $22,115(29.0)$ & $37,003(22.4)$ \\
\hline \multicolumn{3}{|l|}{ Primary Cause ESRD ${ }^{b}(n, \%)$} \\
\hline Diabetes & $37,345(49.0)$ & $89,971(54.6)$ \\
\hline Hypertension & $17,505(23.0)$ & $39,780(24.1)$ \\
\hline Glomerular & $7,724(10.1)$ & $11,118(6.7)$ \\
\hline Cystic & $1,569(2.1)$ & $2,448(1.5)$ \\
\hline Other/Unknown & 12,085 (15.9) & $21,605(13.1)$ \\
\hline \multicolumn{3}{|c|}{ Co-morbid Conditions (n,\% with condition) } \\
\hline Congestive heart failure & $18,501(24.5)$ & $61,259(37.3)$ \\
\hline Ischemic heart disease & $10,961(14.5)$ & $48,848(29.8)$ \\
\hline Cerebrovascular accident & $4,673(6.2)$ & $19,178(11.7)$ \\
\hline Peripheral vascular disease & $7,634(10.1)$ & $30,571(18.6)$ \\
\hline $\begin{array}{l}\text { Chronic obstructive } \\
\text { pulmonary disease }\end{array}$ & $3,346(4.4)$ & $15,508(9.4)$ \\
\hline Tobacco abuse & $6,088(8.1)$ & $9,693(5.9)$ \\
\hline Drug dependence & $2,014(2.7)$ & $842(0.5)$ \\
\hline Cancer & $1,994(2.6)$ & $9,880(6.0)$ \\
\hline HIV no AIDS & $822(1.7)$ & $481(0.4)$ \\
\hline HIV with AIDS & $1,383(2.8)$ & $2,408(2.2)$ \\
\hline Non-ambulatory & $1,964(2.6)$ & $7,504(4.6)$ \\
\hline
\end{tabular}

${ }_{\mathrm{a}} \mathrm{p}<0.001$ for all characteristics.

${ }^{b} E S R D=$ end-stage renal disease.

${ }^{\mathrm{C}}$ ESRD networks not shown. 


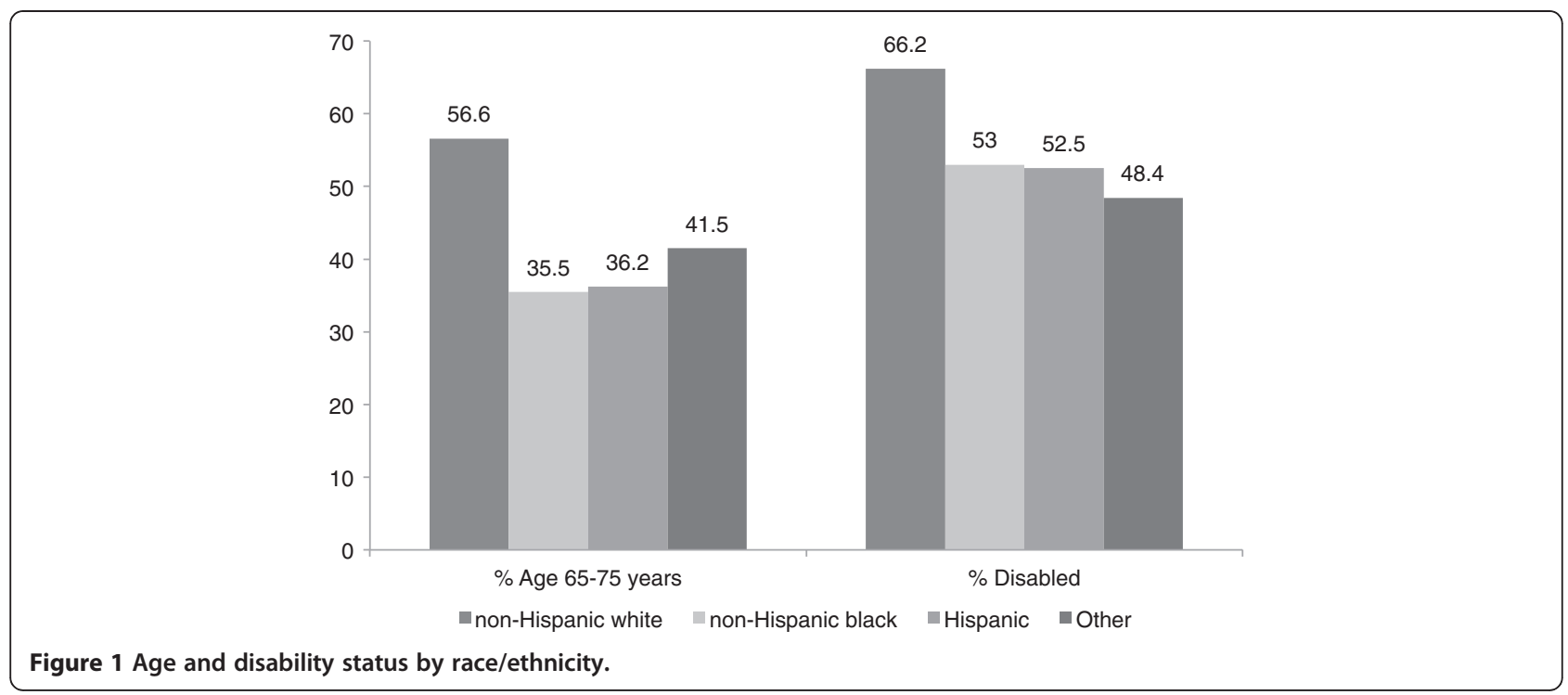

ITS analysis revealed that changes in the likelihood of waitlisting over the study period differed significantly between the age $<65 /$ non-disabled and age $\geq 65 /$ disabled groups $(\mathrm{p}<0.001)$. However, as shown in Table 2 , there was no evidence for changes in the slope for likelihood of waitlisting at the time of policy change $(1 / 1 / 01)$ within either group in the full ITS model (both $\mathrm{p}>0.350)$. In an intermediate model, which included group-specific changes in likelihood of waitlisting at policy change and overall secular time trends across the entire study period from January1998 through November 2003 , there was no evident trend in the $<65 /$ non-disabled group (HR per increase of 1 year, 1.00, 95\% CI 0.98-1.02, $\mathrm{p}=0.989$ ). In the final model, which omitted this nonsignificant time trend, we found a substantial systematic decrease in likelihood of waitlisting at the beginning of 2001 in the $<65 /$ non-disabled group (HR for the immediate effect of policy change, 0.93 , 95\% CI 0.89 $0.97, p=0.002$ ). In the $\geq 65 /$ disabled group, we found strong evidence for an increasing overall trend throughout the study period (HR 1.04 per year, 1.02-1.07, $\mathrm{p}<0.001)$. There was a slight downward, but nonstatistically significant, change in the probability of waitlisting at the beginning of 2001 (HR for the immediate effect of policy change, $0.93,0.85-1.02, \mathrm{p}=0.135$ ), after accounting for the significant time trend in the $\geq 65 /$ disabled group. The adjusted probability of waitlisting by age/disability status and quarter, as well as the time trends based on the final model, are shown in Figure 2.

Those who were non-Hispanic black (vs. non-Hispanic white), were female, or lived in a ZIP code-defined area with lower income were less likely to be waitlisted (Table 3). Additionally, those with comorbid illnesses or disability were less likely to be waitlisted than their

Table 2 Hazard ratios (HR) of waitlisting before policy change, after policy change (in 2001), and for the pre-/postdifference in waitlisting, by age/disability status and year

\begin{tabular}{|c|c|c|c|c|c|c|c|c|c|}
\hline \multirow[b]{2}{*}{ Model } & \multirow[b]{2}{*}{ Group } & \multicolumn{5}{|l|}{ Secular trend } & \multicolumn{3}{|c|}{ Pre-post difference } \\
\hline & & Period & HR & $95 \% \mathrm{Cl}$ & P-value & $\mathbf{P} \#^{\mathbf{b}}$ & $\mathrm{HR}$ & $95 \% \mathrm{Cl}$ & P-value \\
\hline \multirow[t]{4}{*}{ Full ITS ${ }^{a}$ Model } & $<65 /$ non-disabled & before policy change & 1.00 & $0.97-1.02$ & 0.681 & 0.364 & 0.91 & $0.83-1.00$ & 0.063 \\
\hline & & after policy change & 1.02 & $0.98-1.06$ & 0.418 & & & & \\
\hline & $\geq 65 /$ disabled & before policy change & 1.05 & $1.02-1.08$ & $<0.001$ & 0.515 & 0.94 & $0.85-1.04$ & 0.220 \\
\hline & & after policy change & 1.03 & $0.99-1.08$ & 0.123 & & & & \\
\hline \multirow[t]{2}{*}{ Intermediate Model } & $<65 /$ non-disabled & overall & 1.00 & $0.98-1.02$ & 0.989 & - & 0.93 & $0.85-1.01$ & 0.099 \\
\hline & $\geq 65 /$ disabled & overall & 1.04 & $1.02-1.07$ & $<0.001$ & - & 0.93 & $0.84-1.02$ & 0.135 \\
\hline \multirow[t]{2}{*}{ Final Model } & $<65 /$ non-disabled & - & - & - & - & - & 0.93 & $0.89-0.97$ & 0.002 \\
\hline & $\geq 65 /$ disabled & overall & 1.04 & $1.02-1.07$ & $<0.001$ & - & 0.93 & 0.84-1.02 & 0.135 \\
\hline
\end{tabular}

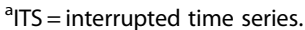

${ }^{\mathrm{b}} \mathrm{P} \#=\mathrm{P}$-value for the equality of the within-group trends before and after policy change. 


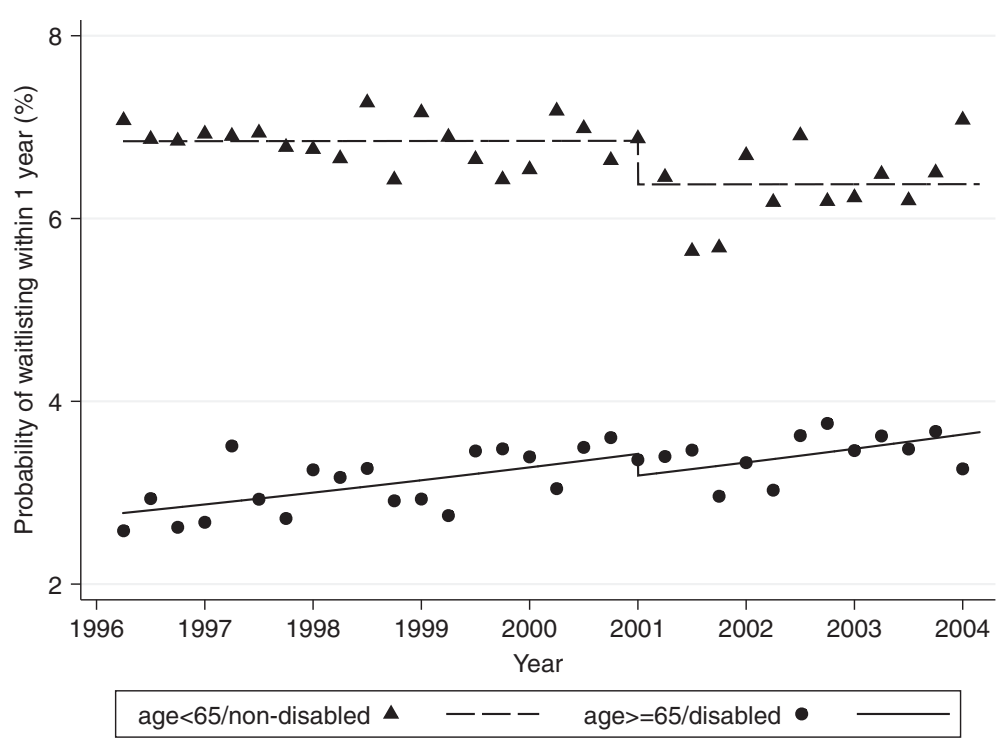

Figure 2 Probability of waitlisting before and after policy change (in 2001) by age/disability status and quarter, adjusted for covariate means. Lines represent estimated trends from final model of interrupted time series analysis.

counterparts without these conditions. Waitlisting was more likely (up to 3 -fold) among those with a primary cause of ESRD other than diabetes.

\section{Discussion}

We expected that the most recent extension of Medicare immunosuppressant coverage would increase waitlisting among older/disabled beneficiaries who would always have insurance coverage for immunosuppressants, but would decrease waitlisting among younger/non-disabled beneficiaries who might not be able to afford their medications when Medicare eligibility ended at 3 years post transplant. After accounting for existing secular trends in waitlisting in a large national database, we found that the policy change did not appear to affect the already increasing access to the kidney transplant waitlist for the older/disabled beneficiaries, but did appear to decrease access for the younger/non-disabled beneficiaries.

While there is no absolute limit to the number of candidates who can be placed on the kidney transplant waitlist, the waitlist is restricted to those candidates transplant centers deem appropriate to receive the limited supply of transplantable organs. Historically, older kidney transplant candidates and those with extra-renal co-morbidities have been considered less ideal transplantation candidates, due to presumed reduced post-transplant functioning and survival [11-18]. Because transplant recipients who are unable to afford their medications are at increased risk of medication noncompliance and subsequent graft loss [6-8], it is conceivable that the extension of lifetime immunosuppressant coverage to $\geq 65 /$ disabled Medicare beneficiaries would improve this group's transplant candidacy appeal but would lessen that of younger/nondisabled patients with limited drug coverage, despite generally better overall health status. In other words, in anticipation of which patients will best care for the limited pool of deceased donor kidneys, transplant programs may be more inclined to waitlist older/disabled Medicare beneficiaries since the implementation of lifetime immunosuppressant coverage, but less inclined to waitlist the younger/non-disabled candidates who would lose Medicare coverage 3 years after transplant. Our findings of decreased waitlisting among the younger/ non-disabled group after the policy change and increasingly lower likelihood of waitlisting with lower area income category support this assertion. This assertion is further supported by a recent study finding that most (67.3\%) U.S. transplant programs report that they frequently or occasionally do not waitlist patients who are perceived to be unable to afford their immunosuppressant medications [30].

Historically, the explicit rationale for differentiating between those with and without existing Medicare eligibility was that those under age 65 and disabled only because of ESRD were expected to return to work because successful transplant was considered 'rehabilitation' [31]. However, return to work is uncommon post-transplant, especially among recipients not working prior to transplant, due to functional limitations and poor health status [32,33]; and finding work that provides private insurance is even less common [34].

Further, legislation for immunosuppressant coverage was established when post-transplant drugs were considered by some to be experimental, and 1-year graft 
Table 3 Hazard ratios (HR) of covariates, final model ${ }^{\mathrm{a}}$

\begin{tabular}{|c|c|c|c|}
\hline & HR & $95 \% \mathrm{Cl}$ & P-value \\
\hline \multicolumn{4}{|l|}{ Gender } \\
\hline Male & 1.0 & & \\
\hline Female & 0.75 & $0.72-0.78$ & $<0.001$ \\
\hline \multicolumn{4}{|l|}{ Race/ethnicity } \\
\hline Non-Hispanic white & 1.0 & & \\
\hline Non-Hispanic black & 0.82 & $0.78-0.86$ & $<0.001$ \\
\hline Hispanic & 1.16 & $1.09-1.22$ & $<0.001$ \\
\hline Other & 1.25 & $1.16-1.35$ & $<0.001$ \\
\hline \multicolumn{4}{|l|}{ ZIP code-level income quartile } \\
\hline$>75^{\text {th }}$ percentile & 1.0 & & \\
\hline 50-75 $5^{\text {th }}$ percentile & 0.90 & $0.86-0.95$ & $<0.001$ \\
\hline $25-50^{\text {th }}$ percentile & 0.85 & $0.81-0.89$ & $<0.001$ \\
\hline$<25^{\text {th }}$ percentile & 0.72 & $0.68-0.76$ & $<0.001$ \\
\hline \multicolumn{4}{|l|}{ Primary cause of ESRD } \\
\hline Diabetes & 1.0 & & \\
\hline Hypertension & 1.28 & $1.22-1.34$ & $<0.001$ \\
\hline Glomerular & 2.50 & $2.38-2.62$ & $<0.001$ \\
\hline Cystic & 2.99 & $2.75-3.24$ & $<0.001$ \\
\hline Other & 1.37 & $1.29-1.45$ & $<0.001$ \\
\hline Unknown & 1.46 & $1.33-1.61$ & $<0.001$ \\
\hline \multicolumn{4}{|l|}{ Co-morbid conditions $^{\mathrm{b}}$} \\
\hline Congestive heart failure & 0.59 & $0.56-0.62$ & $<0.001$ \\
\hline Ischemic heart disease & 0.68 & $0.64-0.72$ & $<0.001$ \\
\hline Cerebrovascular accident & 0.60 & $0.54-0.65$ & $<0.001$ \\
\hline Peripheral vascular disease & 0.68 & $0.63-0.73$ & $<0.001$ \\
\hline Chronic obstructive pulmonary disease & 0.47 & $0.42-0.53$ & $<0.001$ \\
\hline Tobacco abuse & 0.84 & $0.78-0.91$ & $<0.001$ \\
\hline Drug dependence & 0.35 & $0.29-0.39$ & $<0.001$ \\
\hline Cancer & 0.33 & $0.29-0.39$ & $<0.001$ \\
\hline HIV no AIDS & 0.09 & $0.04-0.18$ & $<0.001$ \\
\hline HIV with AIDS & 0.65 & $0.54-0.78$ & $<0.001$ \\
\hline Non-ambulatory & 0.32 & $0.26-0.39$ & $<0.001$ \\
\hline
\end{tabular}

${ }^{a}$ ESRD networks not shown.

${ }^{\mathrm{b}}$ Reference $=$ no condition.

survival was only $40 \%$ [35]. Now that renal transplant 5year survival is upward of $80 \%$ and is associated with better quality of life than dialysis, transplantation has become the preferred treatment for ESRD [36]. Several studies have shown that, despite the significant cost of transplantation itself, post-transplant care and immunosuppressants, transplantation is more cost-effective than dialysis [5,35,36]. While Medicare spends a total of $\$ 73,008$ and $\$ 53,446$ per patient year of hemodialysis and peritoneal dialysis, respectively, only $\$ 24,572$ per patient year is spent on kidney transplant [37]. Because Medicare resumes dialysis payments after transplant graft failure-which may be precipitated by limited coverage for immunosuppressant medications-current policy may be creating greater expense for the Medicare program through excess return to dialysis among $<65 /$ non-disabled patients. Our findings should be considered within the context of cost-effectiveness for the Medicare program, the primary payer for dialysis and transplantation in this country, and as part of the ongoing health care reform debate.

Because racial/ethnic minority ESRD patients are disproportionately younger and non-disabled than nonHispanic whites, minorities may more often suffer decreased access under current policy. We found that non-Hispanic blacks in particular (but not other minorities) were less likely to be waitlisted than non-Hispanic whites. As evidenced in our study, racial/ethnic minorities are more likely to develop ESRD at a younger age than their non-Hispanic white counterparts [38-40] and are therefore further from aging into Medicare eligibility.

\section{Limitations}

Our study is not without limitations. Disability status was determined from the employment status variable. Information regarding underlying cause of disability was not available. Therefore, we were not able to differentiate between disability status due to ESRD and disability for another reason, which may have significantly inflated proportions truly eligible for unlimited immunosuppressant coverage fulfilled by the criterion disability not due to ESRD. This misclassification may have been most pronounced among minority patients given their younger age at ESRD onset, increasing the likelihood that their disability was ESRD-related. However, the likely effect of this misclassification would be to attenuate the observed relationship between policy change and the likelihood of waitlisting among $\geq 65$ /disabled versus $<65 /$ non-disabled patients. Thus, the true impact of the policy on access to transplantation may be underestimated. Additionally, some patients may have obtained private insurance after 90 days of initiating dialysis (when we defined insurance status); however, we expect this is very low in our 12-month observation period given the "pre-existing condition" of end-stage renal disease, which likely excluded many patients at that time from affordable private insurance plans.

It is also possible that factors other than the policy change are also contributing to the observed trends in waitlisting of the $\geq 65 /$ disabled population compared to the $<65 /$ non-disabled population. For example, provider attitudes regarding an upper age limit for transplantation could have changed over time in favor of older applicants, independent of the availability of lifetime immunosuppressant coverage. Also, the implementation of policy for acceptance of expanded criteria donor (ECD) 
kidneys in late 2002 may have also played a partial role in observed rates [41]; however, there was only a $15 \%$ increase in the number of ECD transplants [42] during this study period, and not all ECD kidneys go to the $\geq 65 /$ disabled population [43]. Anticipation of the policy change could also be contributing to the steady increase over time in likelihood of waitlisting for the $\geq 65$ /disabled group-a finding that may reflect increasing patient and provider awareness of the policy and its ramifications. Such possibilities could not be examined here, given the limitations of the data, but future studies examining more recent trends in waitlisting, as well as reasons for waitlisting or not waitlisting potential transplant candidates, may help elucidate underlying causes.

Lastly, we recognize that waitlisting is but one step in access to kidney transplantation. Many factors, such as blood type and pre-formed antibodies, are important determinants of receiving a kidney transplant. Because these factors are only routinely measured in waitlisted candidates, they were largely missing in our dataset, rendering us unable to test our hypothesis in the entire ESRD population.

\section{Conclusions}

In summary, our study suggests that the most recent Medicare coverage extension did not appear to change the already increasing access to the kidney transplant waitlist for the $\geq 65$ / disabled beneficiaries eligible for the benefit but may have decreased access for the $<65 /$ non-disabled beneficiaries who were not. Therefore, the potential ramifications of policies on candidacy appeal for access to kidney transplantation should be considered.

\section{Competing interests}

The authors declare they have no competing interests.

\section{Authors' contributions}

VG acquired the data, participated in study design and statistical analysis and interpretation of the data, and drafted the manuscript. LCP and EV participated in statistical analysis and interpretation of the data and critical revision of the manuscript. $A M O$ and RAD participated in study design and critical revision of the manuscript. All authors have read and approved the final manuscript.

\section{Disclaimer}

The data reported here have been supplied by the United States Renal Data System (USRDS). The interpretation and reporting of these data are the responsibility of the author(s) and in no way should be seen as an official policy or interpretation of the U.S. government.

\section{Funding/ Support}

VG was supported by National Institutes of Health/ National Institute of Diabetes and Digestive and Renal Diseases Diversity Supplement to R01 DK70939 and by the Harold Amos Medical Faculty Development Program of the Robert Wood Johnson Foundation. RAD was supported by an Investigator Award in Health Policy from the Robert Wood Johnson Foundation.

\section{Author details}

'Division of Nephrology, University of California San Francisco, San Francisco General Hospital, San Francisco, CA, USA. ${ }^{2}$ Department of Epidemiology,
Emory University Rollins School of Public Health, Atlanta, GA, USA. ${ }^{3}$ Department of Epidemiology \& Biostatistics, University of California San Francisco, San Francisco, CA, USA. ${ }^{4}$ University of Washington, Nephrology and Veterans Administration Puget Sound Healthcare System, Seattle, WA USA. ${ }^{5}$ Pulmonary and Philip R. Lee Institute for Health Policy Studies, University of California San Francisco, San Francisco, CA, USA.

Received: 15 March 2012 Accepted: 12 August 2012

Published: 16 August 2012

\section{References}

1. United Network for Organ Sharing. http://www.unos.org/data/about/ viewDataReports.asp. Accessed 20 July 2009.

2. Gordon EJ: The ethics of Medicare policy: increasing transplant access and survival. DePaul Law Review Spring 2006, 55(3):1045-1066.

3. Alexander GC, Sehgal AR: Barriers to cadaveric renal transplantation among blacks, women, and the poor. JAMA 1998, 280(13):1148-1152.

4. Braveman P: Health disparities and health equity: concepts and measurement. Annu Rev Public Health 2006, 27:167-194.

5. Yen EF, Hardinger K, Brennan DC, Woodward RS, Desai NM, Crippin JS, Gage BF, Schnitzler MA: Cost-effectiveness of extending Medicare coverage of immunosuppressive medications to the life of a kidney transplant. Am Transplant 2004, 4(10):1703-1708.

6. De Geest S, Borgermans L, Gemoets H, Abraham I, Vlaminck H, Evers G, Vanrenterghem Y: Incidence, determinants, and consequences of subclinical noncompliance with immunosuppressive therapy in renal transplant recipients. Transplantation 1995, 59(3):340-347.

7. Michelon TF, Piovesan F, Pozza R, Castilho C, Bittar AE, Keitel E, Santos A, Goldani JC, Garcia CD, Neumann J, et al: Noncompliance as a cause of renal graft loss. Transplant Proc 2002, 34(7):2768-2770.

8. Morrissey PE, Reinert S, Yango A, Gautam A, Monaco A, Gohh R: Factors contributing to acute rejection in renal transplantation: the role of noncompliance. Transplant Proc 2005, 37(5):2044-2047.

9. Woodward RS, Schnitzler MA, Lowell JA, Spitznagel EL, Brennan DC: Effect of extended coverage of immunosuppressive medications by medicare on the survival of cadaveric renal transplants. Am J Transplant 2001, 1 (1):69-73.

10. Woodward RS, Page TF, Soares R, Schnitzler MA, Lentine KL, Brennan DC: Income-related disparities in kidney transplant graft failures are eliminated by Medicare's immunosuppression coverage. Am J Transplant 2008, 8(12):2636-2646.

11. Hartmann EL, Kitzman D, Rocco M, Leng X, Klepin H, Gordon M, Rejeski J, Berry M, Kritchevsky S: Physical function in older candidates for renal transplantation: an impaired population. Clin J Am Soc Nephrol 2009, 4 (3):588-594.

12. Meier-Kriesche HU, Ojo AO, Cibrik DM, Hanson JA, Leichtman AB, Magee JC, Port FK, Kaplan B: Relationship of recipient age and development of chronic allograft failure. Transplantation 2000, 70(2):306-310.

13. Rao PS, Merion RM, Ashby VB, Port FK, Wolfe RA, Kayler LK: Renal transplantation in elderly patients older than 70 years of age: results from the Scientific Registry of Transplant Recipients. Transplantation 2007, 83(8):1069-1074

14. Saidi RF, Kennealey PT, Elias N, Kawai T, Hertl M, Farrell M, Goes N, Hartono C, Tolkoff-Rubin N, Cosimi AB, et al: Deceased donor kidney transplantation in elderly patients: is there a difference in outcomes? Transplant Proc 2008, 40(10):3413-3417.

15. Danovitch G, Savransky E: Challenges in the counseling and management of older kidney transplant candidates. Am J Kidney Dis 2006, 47(4 Suppl 2): S86-S97.

16. Fabrizii V, Winkelmayer WC, Klauser R, Kletzmayr J, Saemann MD, Steininger R, Kramar R, Horl WH, Kovarik J: Patient and graft survival in older kidney transplant recipients: does age matter? J Am Soc Nephrol 2004, 15 (4):1052-1060

17. Singh N, Nori U, Pesavento T: Kidney transplantation in the elderly. Curr Opin Organ Transplant 2009, 14(4):380-385.

18. Gaylin DS, Held PJ, Port FK, Hunsicker LG, Wolfe RA, Kahan BD, Jones CA, Agodoa LY: The impact of comorbid and sociodemographic factors on access to renal transplantation. JAMA 1993, 269(5):603-608.

19. Wu C, Evans I, Joseph R, Shapiro R, Tan H, Basu A, Smetanka C, Khan A, McCauley J, Unruh M: Comorbid conditions in kidney transplantation: 
association with graft and patient survival. J Am Soc Nephrol 2005, 16 (11):3437-3444.

20. Sweet SC, Wong HH, Webber SA, Horslen S, Guidinger MK, Fine RN, Magee JC: Pediatric transplantation in the United States, 1995-2004. Am J Transplant 2006, 6(5 Pt 2):1132-1152.

21. OPTN/SRTR: Transplant Recipient Characteristics, 1998 to 2007 Recipients of Deceased Donor non-ECD Kidneys. 2008.

22. Kasiske BL, Snyder JJ, Matas AJ, Ellison MD, Gill JS, Kausz AT: Preemptive kidney transplantation: the advantage and the advantaged. J Am Soc Nephrol 2002, 13(5):1358-1364.

23. Keith $D$, Ashby VB, Port FK, Leichtman AB: Insurance type and minority status associated with large disparities in prelisting dialysis among candidates for kidney transplantation. Clin J Am Soc Nephrol 2008, 3 (2):463-470.

24. Ayanian JZ, Cleary PD, Weissman JS, Epstein AM: The effect of patients' preferences on racial differences in access to renal transplantation. $N$ Engl J Med 1999, 341(22):1661-1669.

25. Ashby V, Kalbfleisch J, Wolfe R, Lin M, Port F, Leichtman A: Geographic variability in access to primary kidney transplantation in the United States, 1996-2005. Am J Transplant 2007, 7(Part 2):1412-1423.

26. Biglan A, Ary D, Wagenaar AC: The value of interrupted time-series experiments for community intervention research. Prev Sci 2000, 1(1):31-49.

27. Bonell CP, Hargreaves J, Cousens S, Ross D, Hayes R, Petticrew M, Kirkwood BR: Alternatives to randomisation in the evaluation of public health interventions: design challenges and solutions. J Epidemio/ Community Health 2011, 65(7):582-587

28. Eccles M, Grimshaw J, Campbell M, Ramsay C: Research designs for studies evaluating the effectiveness of change and improvement strategies. Qual Saf Health Care 2003, 12(1):47-52.

29. West SG, Duan N, Pequegnat W, Gaist P, Des Jarlais DC, Holtgrave D, Szapocznik J, Fishbein M, Rapkin B, Clatts M, et al: Alternatives to the randomized controlled trial. Am J Public Health 2008, 98(8):1359-1366.

30. Evans RW, Applegate WH, Briscoe DM, Cohen DJ, Rorick CC, Murphy BT, Madsen JC: Cost-related immunosuppressive medication nonadherence among kidney transplant recipients. Clin J Am Soc Nephrol 2010, 5 (12):2323-2328.

31. Gordon EJ, Prohaska TR, Sehgal AR: The financial impact of immunosuppressant expenses on new kidney transplant recipients. Clin Transplant 2008, 22(6):738-748.

32. Matas AJ, Lawson W, McHugh L, Gillingham K, Payne WD, Dunn DL, Gruessner RW, Sutherland DE, Najarian JS: Employment patterns after successful kidney transplantation. Transplantation 1996, 61(5):729-733.

33. Manninen DL, Evans RW, Dugan MK: Work disability, functional limitations, and the health status of kidney transplantation recipients posttransplant. Clin Transp/ 1991, :193-203.

34. Rettig R, Levinsky N: Kidney failure and the federal government. Washington, D.C: National Academy Press; 1991.

35. Kasiske BL, Cohen D, Lucey MR, Neylan JF: Payment for immunosuppression after organ transplantation. American Society of Transplantation. JAMA 2000, 283(18):2445-2450.

36. Committee on Medicare Coverage Extensions DoHCS: Immunosuppressive Drugs for Transplant Patients. In Extending Medicare Coverage for Preventive and Other Services. Edited by Field M, Lawrence R, Zwanziger L. Washington DC: National Academy Press; 2000:99-126.

37. U.S. Renal Data System: USRDS Annual Data Report. Bethesda: Atlas of Chronic Kidney Disease and End-Stage Renal Disease in the United States; 2009

38. Brancati FL, Whittle JC, Whelton PK, Seidler AJ, Klag MJ: The excess incidence of diabetic end-stage renal disease among blacks. A population-based study of potential explanatory factors. JAMA 1992, 268 (21):3079-3084.

39. Klag MJ, Whelton PK, Randall BL, Neaton JD, Brancati FL, Stamler J: Endstage renal disease in African-American and white men. 16-year MRFIT findings. JAMA 1997, 277(16):1293-1298.

40. Tarver-Carr ME, Powe NR, Eberhardt MS, LaVeist TA, Kington RS, Coresh J, Brancati FL: Excess risk of chronic kidney disease among AfricanAmerican versus white subjects in the United States: a populationbased study of potential explanatory factors. J Am Soc Nephrol 2002, 13(9):2363-2370

41. Metzger RA, Delmonico FL, Feng S, Port FK, Wynn JJ, Merion RM: Expanded criteria donors for kidney transplantation. Am J Transplant 2003, 3(Suppl 4):114-125.
42. Sung RS, Guidinger MK, Lake CD, McBride MA, Greenstein SM, Delmonico FL, Port FK, Merion RM, Leichtman AB: Impact of the expanded criteria donor allocation system on the use of expanded criteria donor kidneys. Transplantation 2005, 79(9):1257-1261.

43. OPTN/SRTR: Transplant Recipient Characteristics, 1998 to 2007 Recipients of Deceased Donor Expanded Criteria Donors (ECD) Kidneys. 2008.

doi:10.1186/1472-6963-12-254

Cite this article as: Grubbs et al: Medicare immunosuppressant coverage and access to kidney transplantation: a retrospective national cohort study. BMC Health Services Research 2012 12:254.

\section{Submit your next manuscript to BioMed Central and take full advantage of:}

- Convenient online submission

- Thorough peer review

- No space constraints or color figure charges

- Immediate publication on acceptance

- Inclusion in PubMed, CAS, Scopus and Google Scholar

- Research which is freely available for redistribution

Submit your manuscript at www.biomedcentral.com/submit
C Biomed Central 